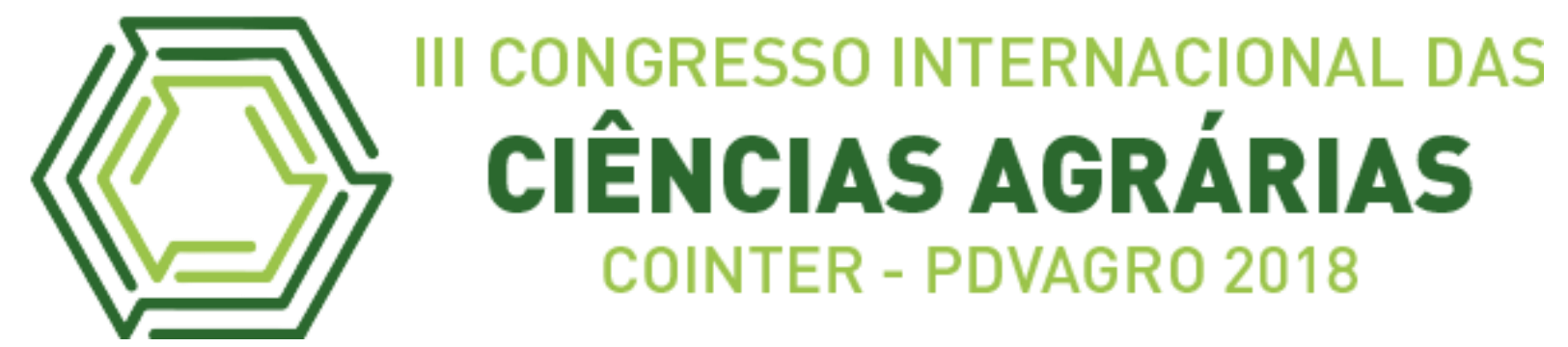

\title{
MICRO-ORGANISMOS EFICIENTES NA PRODUÇÃO DE HORTALIÇAS ORGÂNICAS
}

\section{EFFICIENT MICRO-ORGANISMS IN THE PRODUCTION OF ORGANIC VEGETABLE}

\author{
Apresentação: Relato de Experiência
}

\author{
Gilberto Ednaldo dos Santos Braga ${ }^{1}$; Eronildo Cássio Nemésio Calixto \\ Barbosa $^{2}$;Maciel Alves Tavares ${ }^{3}$; Luan da Costa Avelar Domingues ${ }^{4}$; Vinicius Santos Gomes \\ da Silvar ${ }^{5}$
}

DOI: $\underline{\text { https://doi.org/10.31692/2526-7701.IIICOINTERPDVAGRO.2018.00749 }}$

\section{Introdução}

Os micro-organismos eficientes (EM) são inoculantes formados por fungos e bactérias isolados em matas e que podem influenciar a germinação de sementes. Basicamente quatro grupos de micro-organismos constituem o EM: Leveduras, actinomicetos, bactérias produtoras de ácido lático e bactérias fotossintéticas (PEGORER et al., 1995). O uso de materiais orgânicos é vantajoso, pois melhora as condições químicas e físicas do solo e eleva o nível de fertilidade (OLIVEIRA et al., 2004). Esses compostos proporcionam liberação gradativa dos nutrientes, tendo menos perda para o ambiente (SILVA \& SILVEIRA, 2002).

Há uma tendência mundial que a agricultura seja manejada buscando a sustentabilidade, as pessoas têm seguido fortemente a escolha pelo consumo de alimentos livres de agrotóxicos, porém as tecnologias de produção nessa área ainda são pouco acessíveis aos produtores, isto se justifica principalmente pela falta de incentivo para atividades de Assistência técnica e Extensão Rural ou pela ausência de interesse político em ofertar mais investimentos no campo da ciência e tecnologia voltadas para a produção de alimentos limpos.

Ante a essas considerações, objetivou-se com o presente trabalho, divulgar a produção

\footnotetext{
${ }^{1}$ Graduando em Agronomia, Instituto Federal de Pernambuco, gilbertoanoneiro2014@gmail.com

${ }^{2}$ Graduando em Agronomia, Instituto Federal de Pernambuco, eronildocassio26@gmail.com

${ }^{3}$ Graduando em Agronomia, Instituto Federal de Pernambuco, macieltavares15@gmail.com

${ }^{4}$ Graduando em Agronomia, Instituto Federal de Pernambuco, lunavelar2014@gmail.com

${ }^{5}$ Professor, Instituto Federal de Pernambuco, Vinicius.agro2008.1@gmail.com
} 
do Bokashi e a utilização de microrganismos eficazes (EM), em hortas de agricultura familiar no município de Chã Grande - PE.

\section{Relato de Experiência}

O trabalho trata-se de uma experiência vivida no Instituto Federal de Ciência e Tecnologia de Pernambuco - Campus Vitória de Santo Antão na Semana de Agronomia SEMAGRO, realizada em 2016. Ao ser ministrado o minicurso intitulado como: "Produção de Adubos Biológicos", o qual teve como público alvo estudantes, agricultores e profissionais da área (Figura 1 B), no qual, o conteúdo programático envolveu a produção do Bokashi (Figura 1 C), composto orgânico, solarização e revitalização de solos com o uso de material orgânico utilizando como inoculante o EM, tudo isso com uso de metodologias teóricas e práticas. O minicurso teve uma carga horária de oito horas onde $50 \%$ do conteúdo foram realizados em sala de aula com apresentações teóricas e divulgação de trabalhos científicos e a outra metade do conteúdo foi no campo com aulas práticas.

Tudo transcorreu dentro da normalidade e todos os trabalhos foram concluídos com muito êxito, foi registrada a presença ativa de mais de $80 \%$ dos participantes que de acordo com a avaliação no final do minicurso considerou as experiências de relevante importância, principalmente sobre a proposta de multiplicação dos conhecimentos desenvolvida durante o período da capacitação (Figura 1 D),. 


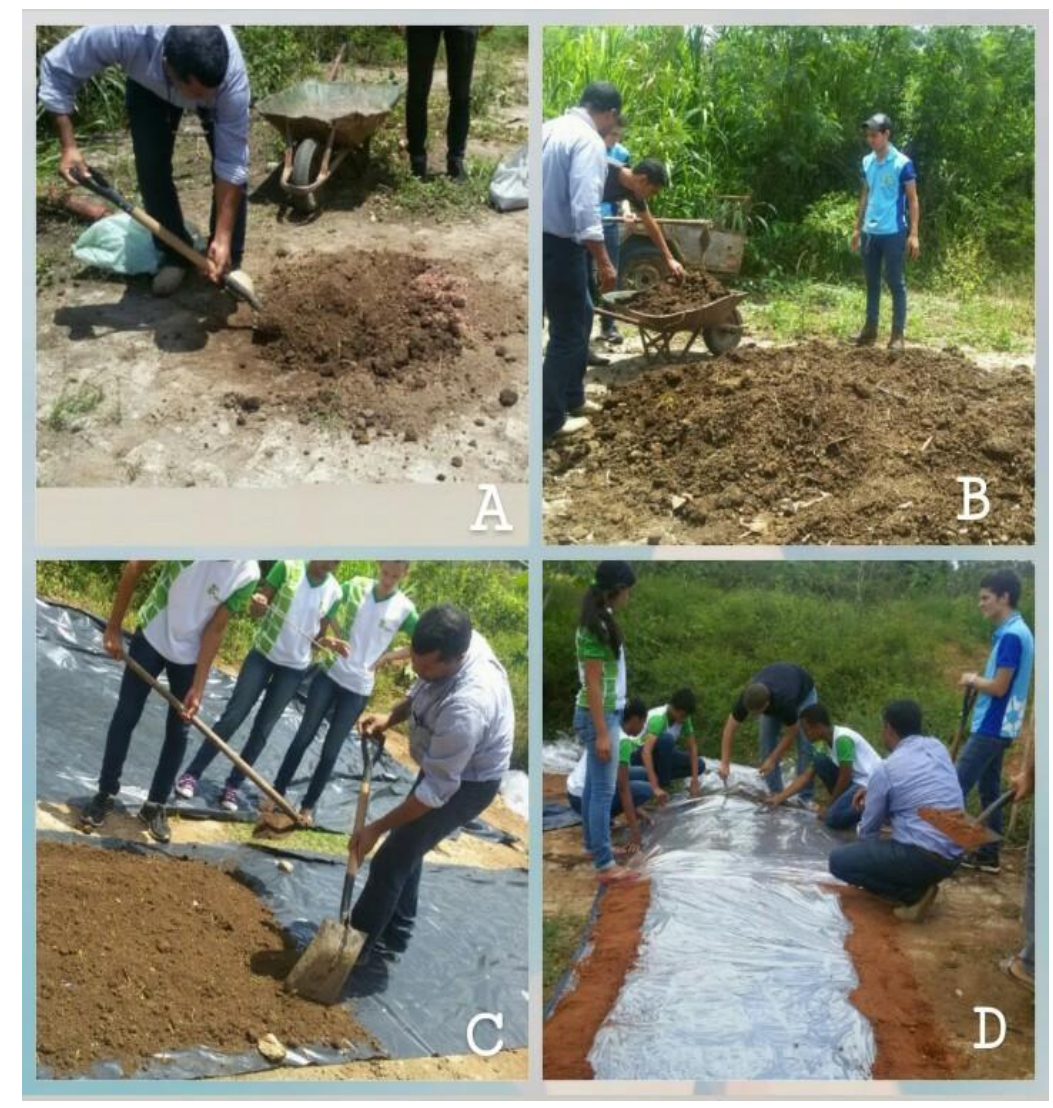

Figura 1: Atividade Experimental. Fonte: Própria

\section{Considerações}

Como considerações finais, temos a ideia principal do minicurso, que consiste na formação de multiplicadores para que as tecnologias vivenciadas pudessem ser difundidas por cada participante em suas comunidades, setores de atuação profissional ou em suas unidades produtivas, como essa ação, se fazer valer o tripé Pesquisa, Ensino e Extensão justamente dentro de uma unidade de formação profissional e produção tecnológica como o Instituto Federal de Pernambuco - Campus Vitória de Santo Antão.

\section{Referências}

BASES PARA NOVA ATER PÚBLICA. Este texto tem como base o capítulo VIII da tese de Doutorado do Autor. Santa Maria: janeiro de 2003. Disponível em < http:coral.ufsm.br/extensaorural/art4ed10.pdf > .

CAPORAL, F.R. A Extensão Rural e os Limites à prática dos extensionistas do serviço público. Dissertação (Mestrado) - Extensão Rural, Universidade Federal de Santa Maria:1991. 
FREIRE, P. Extensão ou Comunicação? Tradução Oliveira, R.D.14a Ed. Rio de Janeiro. Editora Paz e Terra, 2010.

MARIM, V.A.; Baldani, V.L.D.; TEIXEIRA, K.R.S.; Baldani, J.I. Fixação biológica de Nitorgenio: bactérias fixadoras de nitrogênio de importância para agricultura tropical. Série Documentos. EMBRAPA. Agroecologia 32p. 1999.

OLIVEIRA, A. C. B.; SEDIYAMA, M. A. N.; PEDROSA, M. W.; PINHEIRO, N. C.; GARCIA, S. L. R. Divergência genética e descarte de variáveis em alface cultivada sob sistema hidropônico. Revista Acta Scientiarum. Maringá, v. 26, n. 2. 2004. p. 211-217.

PEGORER, A.P.R., FRANCH, C.M.C., FRNCH, J.L., SIQUEIRA;M.F.B., MOTTA, S.D. Informações sobre o uso do E.M. ( Microorganismos Efucazes) - Apostila.

AGRICULTURA NATURAL MESSIÂNICA - Fundação Mokiti Okada - Rio de Janeiro, 1995. $14 \mathrm{p}$.

PEIXOTO, M.M. As Circunstâncias da Criação da Extensão Rural no Brasil. Cadernos de Ciências e Tecnologia, Brasília v.6, n.02, p.97 - 134 maio/ agosto, 1999. Disponível em $<$ http://ser.sct.embrapa.br/índex.php/cct/article/view/8898/5020.

VIERO,Verônica. Crestai; Souza; Renato Santos De. Comunicação Rural on-line: promessas de um mundo sem fronteiras. In: 46th.congress, July 20-23; 2008, Rio Branco Acre, Brasil. Sociedade Brasileira de Economia/ Administração e Socielogia Rural. (SOBER), 2008. 